\title{
Dos paradigmas interculturais à ação educacional autogerida
}

Martha Lucia Izquierdo Barrera

Especialista (Magíster) em Direşão do Desenvolvimento Local; doutoranda do Programa de Ciências da Educação, na linha da Comunicaşão e Pensamento Educativo; diretora do Mestrado em Migrações Internacionais e da Escuela de Ciencias Sociales da Universidad Tecnológica de Pereira em Risaralda, Colômbia.

E-mail: maluiz08@utp.edu.co

Resumo: Este texto pretende relatar a experiência da graduação, em Etnoeducação e Desenvolvimento Comunitário, da Universidad Tecnológica de Pereira, na Colômbia, com as comunidades indígenas Embera Chamí, dos Departamentos de Risaralda e Caldas. Iniciamos com um percurso sócio-histórico e conceitual do surgimento da educação indígena, com a finalidade de contextualizar o leitor no âmbito referido. A segunda parte faz um percurso do contexto institucional - a Facultad de Ciencias de la Educación da Universidad Tecnológica de Pereira e a criação da graduação em Etnoeducação e Desenvolvimento Comunitário. Encerra-se relatando o processo de educação intercultural de uma perspectiva educomunicativa (Entre O CONCEBIDO/O VIVIDO: uma relação para qualificar o olhar).

Palavras-chave: Educação; educação indígena; comunicação; interculturalidade; educomunicação.
Abstract: This paper aims to relate the experience of the Undergraduate Course in Etnoeducation and Community Development of the Technological University of Pereira Colombia with the indigenous community of Embera Chamí in the Risaralda y Caldas Area. We start with a sociohistorical and conceptual discussion, from the emergence of indigenous education, in order to contextualize the reader on the issue we refer. The second part of the paper discusses the institutional context - the Faculty of Educational Sciences of Technological University of Pereira and the creation of the Undergraduate Course in Etnoeducation and Community Development. Finally, we relate the process of intercultural education from the educommunicative, (BETWEEN THE CONCEIVED/LIVED: A relationship to qualify the perspective).

Keywords: Education; Indigenous Education; Communication; Interculturality; Educommunication.

\section{EDUCAÇÃO INDÍGENA: REFERÊNCIAS SÓCIO-HISTÓRICAS E CONCEITUAIS}

Entre os anos de 1900 e 1960, a educação de indígenas era realizada sob a tutela da Igreja ou em escolas oficiais, nas quais era aplicado um currículo que desconhecia a cultura dos grupos étnicos e, na maioria dos casos, impedia que a língua indígena fosse falada.

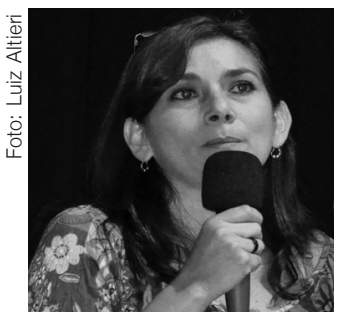

Martha Barrera
Recebido: 05/11/12

Aprovado: 03/12/12 
1. JIMENO, Myrian; TRIANA ANTORVEZA, Adolfo. Estado y minorías étnicas en Colombia [Estado e minorias étnicas na Colômbia]. Bogotá: Cuadernos el jaguar, 1985, p. 31.

2. BUILES, M. A. 1951: 30 apud JIMENO,op. cit, p. 61 .

3. JARAMILLO, 1947: 14, apud JIMENO, op. cit. p. 61.

4. AMODIO, Emanuele. (1989) Escuelas como espadas [Escolas como espadas]. In: AMODIO, Emanuele. (Compilador). Educación, escuelas y culturas indígenas de América Latina [Educação, escolas e culturas indígenas da América Latina]. Quito: Ediciones Abya-Yala, 1989, p. 5-23; BODNAR, Yolanda. (1992). La constitución y la etnoeducación: ¿Una paradoja? [A constituição e a etnoeducação: um paradoxo?]. Educación y cultura, n. 27, p. 20-23, 1992. (Estado, educación y grupos étnicos.); ARTUNDUAGA, Luis Alberto. La etnoeducación: una dimensión de trabajo para la educación en comunidades indígenas de Colombia [A etnoeducação: uma dimensão de trabalho para a educação em comunidades indígenas da Colômbia]. Revista Iberoamericana de educación, n. 13, 1997. (Educación bilingüe. Biblioteca virtual.) Disponível em: http:// www.campus-oei.org/revista/frame_anteriores. htm; AGUIRRE, LICHT, Daniel. ¿Etnoeducación Etnocoacción? [Etnoeducação. Etnocoação?]. In: González Bermúdez, Jorge. Memorias del primer congreso universitario de Etnoeducación [Memórias do primeiro congresso universitário de etnoeducação]. La Guajira: ICFES/ MEN/Universidad, 1988, p. $51-60$.

5. Uma espécie de consetho comunitário (N.T.)
Com o convênio firmado entre o Estado colombiano e a Santa Sé, em 1887, e que se estendeu até depois de meados do século XX, propunham-se normas e diretrizes que tornavam a Igreja Católica um elemento essencial na ordem social e um meio de extensão da civilização e da nacionalidade sobre os "selvagens" e os índios andinos, antigos vassalos seus ${ }^{1}$.

A educação de indígenas, a cargo da Igreja, desenvolveu-se no âmbito das missões, com uma concepção pedagógica originada na pedagogia católica e que se manteve até os anos 1950, época em que foram adotados os planos oficiais.

A partir do convênio de 1887 , a catequese dos selvagens e a educação da juventude passaram a ser os objetivos principais das missões. Por outro lado, a percepção - representações e considerações ideológicas que se tinha das comunidades indígenas - que se havia iniciado na conquista justificava as diversas ações com objetivos civilizadores. De acordo com tais considerações, os indígenas "encontravam-se em um estado inverossímil de degradação: desconheciam o direito à propriedade - base da sociedade -, e seu desconhecimento do matrimônio monogâmico favorecia a promiscuidade sexual com terríveis consequências. Era, portanto, necessário "levar a luz (...) [a] nossos pobres índios [que] vivem tristes, desesperançados (...) [e] não sabem de onde vêm nem para onde vão"'. Impor a "ideia cristã" a povos politeístas em quase sua totalidade - "o que pressupõe uma aberração do entendimento e uma abjeção da natureza racional" - era um compromisso histórico. Apenas assim "o selvagem, livre do jugo da natureza (...) respirou o ar da liberdade (...) e conheceu (...) sua pequenez diante de Deus, que agora lhe alienava o corpo da alma"3.

\section{SURGIMENTO DA EDUCAÇÃO INDÍGENA}

Apesar dos antecedentes de um pensamento pedagógico indígena como o de Manuel Quintín Lame, a escola bilíngue, escola própria ou escola indígena, surgiu apenas nos anos 1970, na Colômbia e também na América Latina, contrariamente e, em muitos casos, por conta da escola oficial e religiosa que havia sido promovida pelo Estado e pela Igreja ${ }^{4}$. As reivindicações indígenas do momento se dirigiam ao reconhecimento de seus direitos em diversos setores e não apenas no plano nacional, mas também internacional.

Assim, próximo ao ano de 1971, seis cabildos $^{5}$ da comunidade Páez, uma das maiores do país (com aproximadamente 120 mil habitantes), formaram o Conselho Regional Indígena do Cauca (CRIC). Tal organização apresentou um programa de lutas que incluía aspectos do ideário de Manuel Quintín Lame, como recuperação das terras em mãos dos latifundiários, consolidação do cabildo indígena, afirmação dos valores culturais dos indígenas.

São seguidos posteriormente pelo Conselho Regional Indígena de Tolima (CRIT), formado por indígenas Pijaos e Coyaimas, e pelo Conselho Regional Indígena de Risaralda (CRIR). Começaram a se reunir no ano de 1975, mas 
só realizaram seu primeiro congresso em torno de 1980 (COLOMBRES, 1977; CRIC, 1978, ICFES, 1985).

As diversas organizações indígenas no ano de 1982 formaram a Organização Nacional Indígena da Colômbia (ONIC). Concebida como uma grande "maloka" de povos indígenas do país, surgiu como resultado de um entendimento entre as comunidades e os povos indígenas colombianos, reunidos no I Congresso Nacional Indígena (ONIC, 2002).

Apesar de que no ideário inicial das organizações indígenas existia uma evidente preocupação com uma educação que defendesse a cultura e a língua, será apenas no final da década de 1970 e meados dos anos 1980 que terão início os programas de educação bilíngue, alguns dos quais controlados por estas organizações, e outros por grupos religiosos (ICFES) ${ }^{6}$.

O conceito de educação indígena refere-se a um processo de socialização endógeno levado a cabo por parte de um grupo étnico, no qual o objetivo é a revalorização da cultura. Neste contexto, cada povo cria sua própria prática educacional, de acordo com sua situação específica.

\section{A CRIAÇÃO DA GRADUAÇÃO EM ETNOEDUCAÇÃO E DESENVOLVIMENTO COMUNITÁRIO}

Por sua vez, a Faculdade de Ciências da Educação estava, nos anos 1990, em uma etapa de crise institucional e acadêmica, que exigia a implantação de uma série de transformações quanto aos paradigmas que orientavam sua ação pedagógica e curricular.

Ainda assim, era necessário pensar em modelos de formação integral, dados os altos níveis de conflito e intolerância que caracterizavam nosso país nos anos 1990. Além disso, havia desafios propostos pela UNESCO, como a formulação dos saberes necessários para a educação do futuro.

Surge, então, a graduação em Etnoeducação e Desenvolvimento Comunitário, na Universidade Tecnológica de Pereira (UTP), no contexto da promulgação da nova Constituição Política de 1991, na qual se reconhecia que a Colômbia era um país de diversidades regionais e pluriétnico. Isso levava ao reconhecimento de uma série de esforços de acadêmicos, pesquisadores e líderes de organizações étnicas, no sentido de atestar a importância de tais grupos étnicos, especialmente indígenas e afrodescendentes, no processo de construção do Estado-Nação na Colômbia.

O reconhecimento desta mestiçagem étnica foi um primeiro passo que permitiu tornar mais visíveis os processos de exclusão, a partir de uma perspectiva histórica, da qual foram "vítimas" os membros de tais etnias durante os anos da Colônia, sob a hegemonia da Coroa Espanhola, como também ao longo do processo de consolidação do Estado republicano moderno, entre os séculos XIX e XX.

6. ENCUENTRO NACIO NAL DE EXPERIENCIAS EN EDUCACIÓN INDÍGENA. ICFES/ Popayán: Universidad del Cauca, 1985). 
comunicação \& educação • Ano XV|l| • número 1 • jan/jun 2013

Nesse contexto, a educação também devia assumir um papel central para fortalecer os nexos identitários dentro de grupos étnicos - que em sua grande maioria corriam o risco de dissolver-se, como resultado da modernização econômica, da penetração dos meios de comunicação em massa e do deslocamento forçado do campo e das zonas selvagens para a cidade, como consequência do conflito social e da confrontação armada entre exército, guerrilhas e paramilitares, e que por longos anos afetou a população civil colombiana. Isso implicava também que (ao mesmo tempo que fortalecia a educação própria, o que permite valorizar sua língua, história e tradições como parte de um diálogo de gerações no âmbito da comunidade) fosse necessário abordar temas como o dos direitos humanos - problemática de profunda repercussão que também afetava outros grupos que sofriam perseguição, tais como sindicalistas, estudantes, militares de organizações de esquerda etc.

Dessa forma, a etnoeducação era um bom pretexto para se propor o desafio da transição étnica da nação e de uma sociedade mais tolerante, gerando outros espaços de diálogo e pedagogias para o reconhecimento intercultural.

Ao longo destes anos, tem sido necessário enfatizar de maneira complementar vários modelos ou paradigmas de educação intercultural. É claro, como diz Adela Cortina, que a educação das pessoas não pode estar desconectada de seus contextos sociais ou comunitários e de seus projetos pessoais; mas, da mesma forma, uma capacidade de relação dialógica com projeção ética e universal.

Como aponta Rosa Marí Ytarte, falar de interculturalidade de uma perspectiva pedagógica significa falar de identidade e de cultura no âmbito de sociedades complexas e interdependentes. Implica ir além dos reducionismos na educação e nos estereótipos culturais. O esforço centra-se no estabelecimento de um equilíbrio entre as diferenças culturais e das possibilidades de articulação. Já não se trata de uma simples relação centro-periferia, culto-popular ou bárbaro-civilizado - dicotomias das quais deram conta as teorias pós-coloniais.

Para nós, da graduação em Etnoeducação e Desenvolvimento Comunitário, é evidente que a aproximação de nossa interculturalidade requer uma análise crítica das estruturas sociais e das mediações culturais, mas também de um alto nível de reflexão - ou subjetividade - sobre a própria história, mas em constante interação com outras formas de ver e entender o mundo. Desse modo, a interculturalidade é assumida a partir de um exercício dialógico e de uma pedagogia comunicativa que integram tanto o reconhecimento da diversidade quanto a adesão a pressupostos comuns baseados na democracia, nos direitos humanos e no desenvolvimento comunitário, cooperativo e solidário.

Entendemos a etnocomunicação sob uma perspectiva de mudança cultural, revolucionária, dialógica, dialética, global, interativa, que nunca se acaba, e que adquire seu pleno sentido quando os envolvidos no processo ensinam e aprendem ao mesmo tempo, pois são alternativamente emissores e receptores. A relação pedagógica transforma-se numa situação de aprendizagem compartilhada entre os que se comunicam entre si e que, ao fazê-lo, constroem um fato 
educacional, cujo principal objetivo é o desenvolvimento de um pensamento crítico diante da situação do mundo e de suas mensagens.

\section{EXPERIÊNCIA DO PROCESSO DE EDUCAÇÃO INTERCULTURAL EM MISTRATÓ E RIOSUCIO: BALANÇO E NOVOS DESAFIOS}

\section{Entre o concebido/o vivido: uma relação para qualificar o ollhar. O contexto formal:}

A população Embera Chamí encontra-se localizada nos departamentos de Risaralda e Caldas, dois departamentos da zona cafeeira e mineira da Colômbia. Estes povoados têm como base de sua organização social a parentela, composta pelo pai, a mãe, os filhos do casal e suas respectivas famílias. O chefe da família é a autoridade do grupo.

Politicamente, sustentam-se no cabildo, o poder das autoridades tradicionais com o Jaibaná, que desempenha uma função de grande importância no manejo da vida mágico-religiosa.

A cosmovisão destas comunidades bem pode ser expressa nos termos utilizados por uma mulher Embera, citada por Vasco Uribe em seu texto Los Embera-Chami en guerra contra los cangrejos [Os Embera-Chamí em guerra com os caranguejos]:

Na cosmovisão Embera, pensa-se que há três mundos: o de cima (bajía), onde estão Karagabí (a lua e pai de Jinopotabar) e Ba (o trovão); o dos huanos, que é a terra (egoró), onde vivem os Embera; e o de baixo (aremuco ou chiapera), ao qual chega-se pela água e que é onde vivem os Dojura, Tuturica, Jinopotabar e os antepassados, e onde se originam os Jaibaná (sábios tradicionais). Jinopotabar une todos os mundos e pode passar de um para o outro com seu trabalho, porque é cure, sábio, Jaibaná. Este mundo tem também três partes, três ordens: a do monte; a da terra, onde vivem os Embera nas margens dos rios; a da água; três componentes que se equivalem e relacionam com os três anteriores. Assim, seus termos extremos, monte e rio, são as vias de comunicação com o mundo de cima e o de baixo, respectivamente. Por isso, Jinopotabar vai ao monte quando quer ir à lua, que navega pelo céu em sua canoa, e ao rio quando quer alcançar o mundo de baixo... O equilíbrio entre estes mundos e as ordens que estão entre eles geram a vida cotidiana Chamí. O que pertence ao mundo de cima deve descer e o que pertence ao de baixo deve subir, ascensão que representa um sair do meio da terra. A água é um elemento de mediação entre os dois mundos, já que se unem o movimento de cair e sair, daqui nasce também a importância dos rios e a localização das comunidades Chamí perto deles. Conta-se que rio acima, na nascente da água, está a selva com toda sua força, com lugares perigosos e temidos, e rio abaixo fica o lugar dos homens onde é possível viver?

Tal contexto, caracterizado por tensões, como exclusão/inclusão, homogeneidade/heterogeneidade, distribuição desigual da riqueza, foi levado ao âmbito educacional, afetando, na maioria dos casos, o desempenho e a permanência das crianças Embera no sistema educacional.

7. URIBE, Vasco. Los Embera-Chami em guerra contra los cangrejos (Os Embera-Chami em guerra com os caranguejos) 1990. 
comunicação \& educação • Ano XV|l| • número 1 • jan/jun 2013

Estas tensões nos levaram, na graduação em Etnoeducação e Desenvolvimento Comunitário, a nos propor e enfrentar o desafio de trabalhar diretamente com as comunidades indígenas e de afrodescendentes, gerando uma série de perguntas: Como enfrentar criativamente tais tensões? Como alcançar uma educação inclusiva nesse panorama heterogêneo multifacetado e cheio de contrastes? Como conseguir passar do slogan às estratégias e metas concretas? De que tipo de educação estas pessoas necessitam? Quem são os sujeitos da aprendizagem etnoeducativa? Deveríamos perguntar também: Quem são os sujeitos do conhecimento etnoeducativo ou intercultural?

Para além da titulação profissional - que, sem dúvida, pode auxiliar nossos estudantes na ascensão profissional -, é claro que nossa contribuição deve se centrar em ajudar a criar uma relação de respeito e reconhecimento a partir de cada cosmovisão, dos saberes próprios e do próprio projeto de vida; deve inclusive produzir maior reconhecimento ou participação na gestão e execução de políticas públicas firmadas entre os diferentes âmbitos de sua vida social ou comunitária.

Aparentemente, o esquema da relação ensino-aprendizagem é bastante simples, mas exige uma grande disposição para interagir entre educandos e educadores, em aspectos como:

- Reconhecimento - mediante a pesquisa - da oralidade, da história própria, dos mitos que ainda se mantêm entre os idosos e os jovens.

- Projetos de vida que fortaleçam a identidade própria, mitiguem a migração campo-cidade, produzam projetos de vida centrados em elementos como segurança alimentar, em processo educacionais e culturais que permitam aos jovens, em plena época de globalização, se reconhecerem e reconhecerem outros modos de vida e identidade individual ou coletiva.

- Estratégias educomunicativas entre estudante/docente/estudante.

- Compreender como viver e entender a interculturalidade.

Não se deve esquecer que, de toda forma, trata-se de um exercício de formação de educadores, o que pressupõe um grau de complexidade na capacidade de desenvolver olhares de primeiro grau (áreas de conhecimento, problemáticas políticas e sociais contemporâneas, história própria etc.), segundo grau (âmbito das relações de educação e comunicação com outros jovens e futuros estudantes) e terceiro grau (seu próprio nível de reflexão e compreensão, como diria Morin).

Dessa forma, procuramos que a aposta na educação intercultural crie um espaço dinâmico, lúdico, reflexivo e construtivo, que permita articular uma reflexão particular do local sobre o global, e sobre noções como sociedade, identidade, cultura, democracia e direitos humanos.

Estávamos conscientes de que diretrizes estabelecidas pelo Ministério de Educação Nacional - referente à estrutura curricular e autonomia escolar - não nos distanciavam de nosso próprio propósito, mas nos ofereciam uma orientação 
para sustentar nossa proposta, segundo o que foi exposto no texto "Estándares para la Excelencia en la Educación” [Modelos para a excelência na educação].

A partir de tais parâmetros, foi possível estabelecer uma estratégia metodológica flexível, permitindo uma construção coletiva entre docente/estudante/ comunidade, com o intercâmbio de processos de aprendizagem e construção de conhecimento. Este esboço, a partir de perguntas orientadoras e recursos pedagógicos já mencionados, nos introduziram no que chamamos "cenário de aprendizagem", baseado em um eixo comunicativo de intercâmbio de relatos entre professores indígenas/estudantes indígenas/professores mestiços, dos quais emergia um novo relato. Os relatos surgidos eram produzidos levando em conta o Projeto de Vida e as mudanças culturais no seu lugar de origem; esta construção metodológica pode ser sintetizada no seguinte esquema:

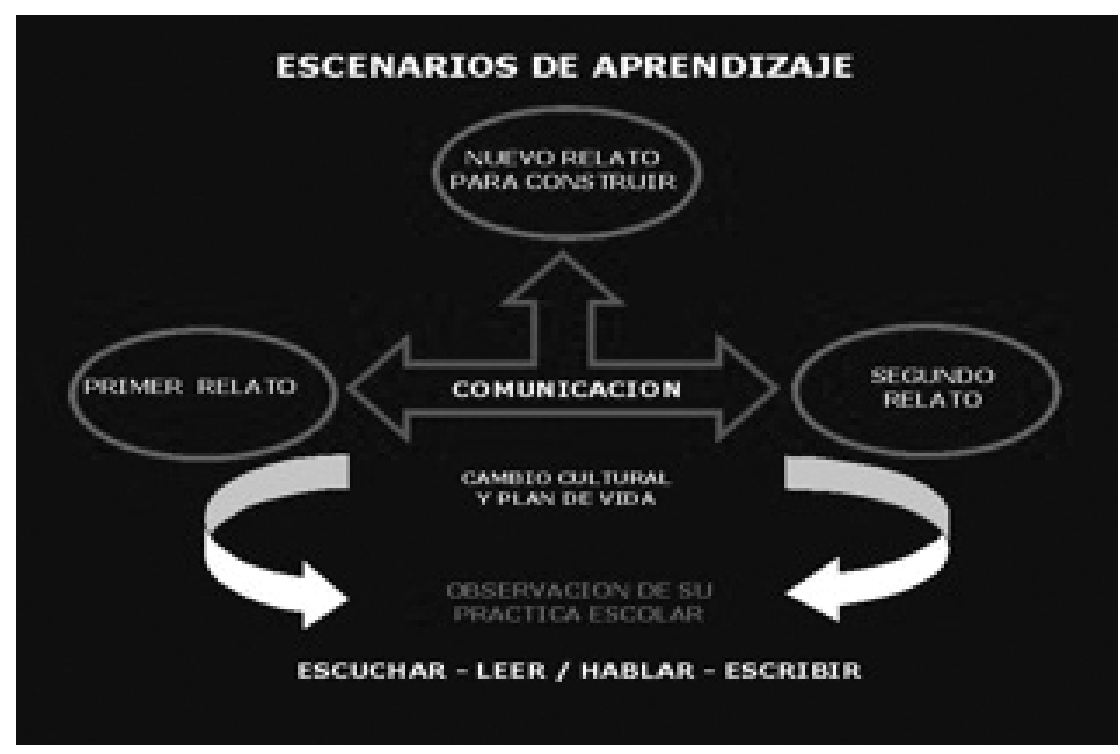

Cenário de aprendizagem.

O cenário de aprendizagem aqui exposto nos permitiu, além de tudo, estimular habilidades lecto-escritoras e oral-auditivas, relacionadas sempre com os assuntos a serem tratados, relacionados, por sua vez, a eixos geradores, perguntas problematizadoras e âmbitos conceituais.

A proposta de resolução de um problema concreto nos situa no horizonte das condições de um aprendizado significativo - na medida em que se motiva a atitude significativa de aprendizagem por parte dos estudantes - relacionado à estrutura cognitiva daquele que aprende de maneira não "arbitrária" e "substantiva", permitindo a interação com o novo conhecimento como "ideias de ancoragem".

O horizonte de aprendizagem significativa proposto por Ausubel distingue três tipos - o de representações, o de conceitos e o de proposições - e está de acordo com a metodologia proposta, que é: interrelacionar um primeiro relato a partir dos conhecimentos prévios dos estudantes, um segundo relato 
que encontre assimilação de um conceito com a prática vivida e um relato emergente no qual sejam combinados conhecimentos prévios, assimilação do novo relato, para fazer um relato emergente significativo.

Como foi possível evidenciar nos parágrafos anteriores, tais relações triádicas, tanto na metodologia quanto na perspectiva teórica, nos ofereceram a possibilidade de estabelecer a proposta para colocar em prática uma estratégia de ensino-aprendizagem, do trabalhar fazendo, aprender fazendo e ensinar produzindo, para conferir significado à relação do concebido/vivido como possibilidade de qualificar o olhar.

\section{VIVENDO OS CENÁRIOS DE APRENDIZAGEM: UM ENFOQUE PEDAGÓGICO-COMUNICATIVO}

Sobre as bases do esboço proposto pela graduação, partiu-se de dois questionamentos: $\mathrm{O}$ que queremos fixar na memória dos estudantes? Como vamos conseguir isso? Para tanto, seriam utilizados recursos pedagógicos da comparação, associação e da ilustração analógica. Tais recursos teriam a intenção de fazer descer o discurso abstrato para torná-lo comunicável aos estudantes e, para isso, era indispensável afinar nossas próprias competências comunicativas, como:

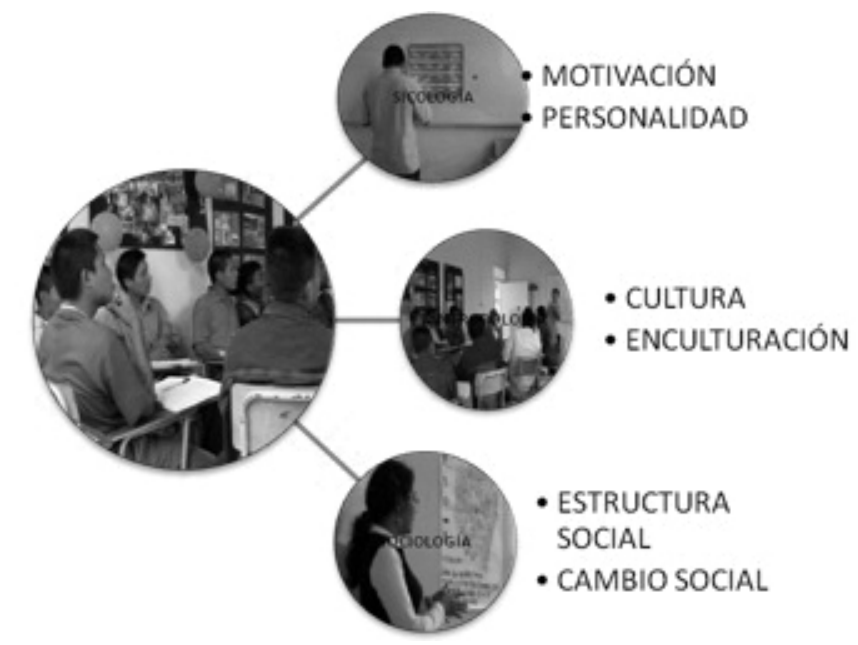

- escuta ativa;

- simplicidade na formulação das mensagens;

- estrutura clara nos aspectos verbais;

- precisão e brevidade nos aspectos verbais;

- coerência entre expressões verbais e não verbais.

Tudo isso sempre conectado à interculturalidade como conceito que tem sido o lugar de chegada e partida de distintos atores docentes que formam a equipe de trabalho da graduação de Etnoeducação e Desenvolvimento Comunitário. 
Sem ser um conceito compartilhado, na medida em que coexistem diferentes pontos de vista e experiências, consolidou-se uma prática de escuta que viabiliza o outro como correlator da experiência compartilhada. Ao diferenciar-se do fazer na sala de aula tradicional, no caso dos docentes de etnoeducação, existe a predisposição para uma escuta cultural que dimensiona os pequenos detalhes e os interstícios do que é comunicado. Não se parte da escuta equiparada à recepção de uma mensagem, em consonância com o universo das subjetividades de quem recebe, mas da escuta como um exercício pleno de comunicação, no qual a disposição de quem o faz permite o paulatino surgimento de códigos comuns que efetivamente conferem ao outro um estatuto de correlator.

É-se correlator na medida em que os dispositivos pertencentes à funcionalidade hegemônica (status, poder, influência, distinção) não são aqueles privilegiados no encontro. O docente não se assume como representante funcional da institucionalidade educacional, pelo contrário, faz um esforço intencional para liberar-se parcialmente dos dispositivos, permitindo ao outro ator (estudante) seu surgimento no correlato.

Quando se reconhece a existência de saberes mediadores do encontro dentro e fora da sala de aula, os mesmos tornam-se um meio para estimular o surgimento de uma escuta cultural comum. Neste âmbito, docente e estudantes participam na redução das prevenções e temores ligados aos dispositivos hegemônicos. O correlato que surge ganha um valor que desloca a centralidade do aspecto temático, para chamar pelos elementos cognitivos ligados à cultura.

Emergem as diferentes formas de aprendizagem, as diversas pautas para a explicação do mundo, as sinergias que na cultura conferem uma qualidade desencadeadora para cada ator. E é precisamente tal qualidade desencadeadora a que fala timidamente, a que ainda não visualizamos de modo manifesto.

A prática de escuta cultural enfrenta diversos obstáculos. No caso da graduação, são os mesmos atores do programa seus primeiros elementos de tensão. $\mathrm{O}$ estudante não chega às salas de aula universitárias preparado para ser ouvido, pois sua experiência no aparelho educacional é de sujeição e invisibilização sob a homogeneidade. Igual dentro da alma mater, compara-se a outros estudantes, sem compreender com clareza por que não recebe no cotidiano uma soma de tensões autoritárias. Ao não esperar ser ouvido, também não realiza o interesse pela escuta, o que aumenta de modo progressivo a tensão entre um docente interessado na escuta e um estudante

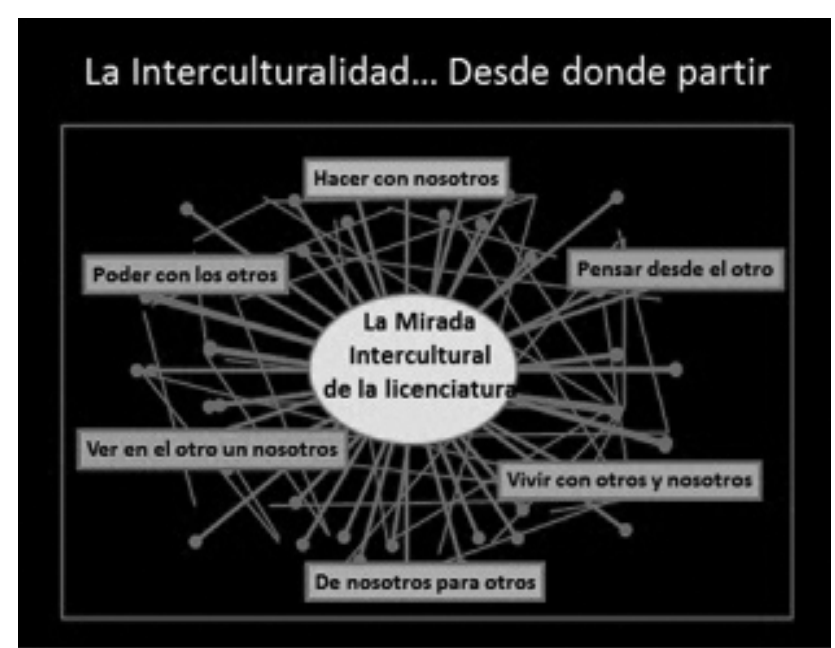

A interculturalidade... de onde partir. 
comunicação \& educação • Ano XV|l| • número 1 • jan/jun 2013

que aguarda a indicação e a bancarização como práticas próprias do cenário da educação.

Outro obstáculo advém da própria estrutura universitária de nosso contexto, que não está pensada para a interação com o outro. Tal estrutura assume-se como um dispositivo técnico que oferece uma preparação básica para um fazer social, sem reclamar-se um papel adicional. Portanto, a forma de planejamento cria rotas que privilegiam a temática, sem dar importância ao significado do encontro educacional. Isso pressiona docentes e estudantes a desempenharem papéis mínimos, formais, que terminam sendo ruídos, ausências e silêncios, que não favorecem uma escuta cultural.

Na graduação, estamos em constante construção de um olhar intercultural através do qual possamos: viver com outros e conosco; de nós para os outros; ver no outro um nós; poder com os outros; fazer conosco e pensar do lugar do outro. Construir a partir dos diferentes campos disciplinares que alimentam as diversas dimensões de ser um nós-outros.

\section{REFERÊNCIAS BIBLIOGRÁFICAS}

ABRAM, Matias. Problemas y perspectivas de la educación bilingüe en el Ecuador [Problemas e perspectivas da educação bilíngue no Equador] In: DE LA TORRE, Luís. Pueblos indígenas y educación [Povos indígenas e educação]. Ecuador: Ediciones Abya-Yala, 1987, p. 5-37.

AGUIRRE, LICHT, Daniel. ¿Etnoeducación Etnocoacción? [Etnoeducação. Etnocoação?]. In: González Bermúdez, Jorge. Memorias del primer congreso universitario de Etnoeducación [Memórias do primeiro congresso universitário de etnoeducação]. La Guajira: ICFES/ MEN/Universidad, 1988, p. 51-60.

AMODIO, Emanuele. (1989) Escuelas como espadas [Escolas como espadas]. In: AMODIO, Emanuele. (Compilador). Educación, escuelas y culturas indígenas de América Latina [Educação, escolas e culturas indígenas da América Latina]. Quito: Ediciones Abya-Yala, 1989, p. 5-23.

ARTUNDUAGA, Luis Alberto. La etnoeducación: una dimensión de trabajo para la educación en comunidades indígenas de Colombia [A etnoeducação: uma dimensão de trabalho para a educação em comunidades indígenas da Colômbia]. Revista Iberoamericana de educación, n. 13, 1997. (Educación bilingüe. Biblioteca virtual.) Disponível em: <http://www.campus-oei.org/revista/frame_anteriores. htm>.

BARNACH-CALBÓ, Ernesto. La nueva educación indígena en Iberoamérica [A nova educação indígena na América Ibérica]. Revista Iberoamericana de Educación, n. 13, 1997. (Educación bilingüe. Biblioteca virtual.) Disponível em: $<$ http://www.campus-oei.org/revista/frame_anteriores.htm>. 
Dos paradigmas interculturais à ação educacional autogerida • Martha Lucia Izquierdo Barrera

BODNAR, Yolanda. (1992). La constitución y la etnoeducación: ¿Una paradoja? [A constituição e a etnoeducação: um paradoxo?]. Educación y cultura, n. 27, p. 20-23, 1992. (Estado, educación y grupos étnicos.)

BOLAÑOS, Graciela. (1999) Proyecto educativo comunitario [Projeto educacional comunitário] - PEC. C’ayuce, n. 3. Popayán: CRIC, 1999, p. 15-20.

Miembro del CRIC. Entrevista telefônica, Junio 23, 2002.

CASTILLO CARDENAS, Gonzalo. Liberation theology from bellow; The life and thought of Manuel Quintín Lame [Teologia da libertação e além: a vida e o pensamento de Manuel Quintín Lame]. New York: Orbits Books/Maryknoll, 1987, 200 pp.

CASTRILLÓN ARBOLEDA, Diego. El Indio Quintín Lame [O índio Quintin Lame]. Bogotá: Tercer Mundo, 1973, 263 pp.

COLOMBRE, Adolfo. Hacia la autogestión indígena [Rumo à autogestão indígena] (documentos). Quito: Ediciones del Sol, 1977, 294 pp.

CONSTITUCIÓN POLÍTICA DE COLOMBIA, 1991.

DECRETO 74, de 1898.

DECRETO 088, de 1976.

DECRETO 1142, de 1978.

DECRETO 1860. Reglamentario de la ley 115, de 1994.

DECRETO 804, de 1995.

DÍAZ-COUDER, Ernesto. Diversidad Cultural y Educación en IberoAmérica. [Diversidade cultural e educação na América Ibérica]. Revista Iberoamericana de Educación. Educación, Lenguas, Culturas, n. 17, Mayo-Agosto 1998. (Versión Virtual.) Disponível em: <http://www.campus-oei.org/revista/frame_anteriores. $\mathrm{htm}>$.

ENCUENTRO NACIONAL DE EXPERIENCIAS EN EDUCACIÓN INDÍGENA. ICFES/ Popayán: Universidad del Cauca, 1986, 220 pp.

JIMENO, Myrian; TRIANA ANTORVEZA, Adolfo. Estado y minorías étnicas en Colombia [Estado e minorias étnicas na Colômbia]. Bogotá: Cuadernos el jaguar, 1985, 343 pp.

HOUGHTON, Juan. ¿A dónde apunta la educación en los pueblos indígenas? [Para onde vai a educação nos povoados indígenas?]. In: TRILLOS, Maria (COMPILADORA). Educación endógena frente a educación formal. [Educação endógena diante da educação formal]. Bogotá: Universidad de los Andes/ CCELA, 1988, p. 51-67.

LEBOT, Ivon. Educación e ideología en Colombia [Educação e ideologia na Colômbia]. Bogotá: La Carreta, 1979, 345 pp. 
comunicação \& educação • Ano XVIII • número 1 • jan/jun 2013

LEY 89, de 1890.

LEY GENERAL DE EDUCACIÓN [Lei Geral da educação]. Ley 115, de 1994.

LINEAMIENTOS GENERALES DE EDUCACIÓN INDÍGENA [Diretrizes Gerais da Educação Indígena]. Bogotá: MEN, 1987, 87 pp.

LOPEZ, Gerardo; VELAZCO, Sergio. Aportaciones indias a la educación. [Contribuições dos índios para a educação]. México: Ediciones El Caballito, 1986, 157 pp.

LÓPEZ, Luis Enrique; KÜPER, Wolfgang. La educación intercultural bilingüe en América Latina: balance y perspectivas. [A educação intercultural indígena na América Latina]. Revista iberoamericana, n. 20, Mayo/Agosto 1999 (OEI: 50 años de cooperación). Disponível em: <http://www.campus-oei.org/revista $>$.

ROMERO, L. Fernando. Limites y singnificaciones pedagógicas [Limites e significados pedagógicos]. In: Para leer la ley General de Educación [Para ler a lei geral de educação]. Bogotá: Ediciones Susaeta, 1994, p. 19-55.

. La educación indígena en Colombia. 1970-2000 [A educação indígena na Colômbia. 1970-2000]. Diálogos educativos, n. 3. Universidad Tecnológica de Pereira. Pereira, p. 81-90, 2002.

et al. La educación bilingüe [A educação bilíngue]. La Piragua. Revista Latinoamérica de educación y política. Valparaíso, Chile, p. 49- 50, 1991. 